\title{
S-shape Wideband Microstrip Patch Antenna with Enhanced Gain and Bandwidth for Wireless Communication
}

\author{
Bharatendra Singh Niboriya \\ M.Tech Scholar \\ Saroj Inst. of Tech. \& Management \\ Lucknow, India
}

\author{
Chetan Choudhary \\ Assistant Professor
}

Saroj Inst. of Tech. \& Management

Lucknow, India

\author{
Gyan Prabhakar \\ Assistant Professor \\ Saroj Inst. of Tech. \& Management \\ Lucknow, India
}

\begin{abstract}
A wideband S-shape microstrip patch antenna is proposed in this paper. The bandwidth is further increased by introducing PBG structure. Low volume and low profile configuration, easily mounted, low fabrication cost and light weight are the advantages of this antenna. With this design, a matching impedance bandwidth over $67.23 \%$ (from $4.0769 \mathrm{GHz}$ to $8.2051 \mathrm{GHz})$ for $\mathrm{VSWR}<2$ was achieved. The proposed antenna operates in S-band and C-band with bandwidth over $1.72 \%$ and $67.23 \%$. The proposed antenna is best suited for Cband communication. The maximum achieved gain of the designed antenna is $6 \mathrm{dBi}$ with return loss of $-33 \mathrm{~dB}$.
\end{abstract}

\section{General Terms}

Microstrip antenna, Wideband operation, FR4 material, Gain.

\section{Keywords}

IE3DTM Simulator, PBG, S-shape patch, Return loss, Bandwidth, S-band, C- Band.

\section{INTRODUCTION}

Microstrip patch antenna is a key building in wireless communication and global positioning system since it was first demonstrated in 1886 by Heinrich Hertz and its practical application by Guglielmo-Marconi in 1901. A microstrip patch antenna offers a low profile, light weight, low fabrication cost, which provides great advantages over traditional antennas [1-2-14]. However, narrow bandwidth came as the major disadvantage for this type of antenna [9]. Several techniques have been applied to overcome this problem such as increasing the substrate thickness, introducing parasitic elements i.e. co-planar or stack configuration, or modifying the shape of the patch [3-5-6].

Modifying patch's shape includes designing of S-shape patch. In particular, the E-shape and C-shape patch have gained a lot of popularity [8-11-14]. The effort made here is to combine these two structures and observing interesting results, which are further improved by using PBG structure. The proposed Sshape MSA is easily formed by cutting two slots from a rectangular shape as shown in fig 1 . By putting the slots from a patch, gain and bandwidth of microstrip antenna can be enhanced [3-6-11-14]. In this designed microstrip antenna the S-shaped patch is placed on the top of the dielectric sheet and the dielectric sheet is placed on a ground plane [2]. The main objective of this paper is to optimize the base design to obtain higher bandwidth. Theoretical simulation and optimization are performed using IE3D simulator.

\section{DESIGN PROCEDURE}

The geometry of the proposed antenna is shown in figure 2 . The S-shape patch has a dimension of $30 \mathrm{~mm} \times 40 \mathrm{~mm}$. It is printed on a FR4 substrate of thickness $1.6 \mathrm{~mm}(\mathrm{~h}) \&$ relative permittivity $4.4\left(\in_{r}\right)$. The patch antenna is coaxially probe fed at $(40,32)$. The width $(\mathrm{W}) \&$ length $(\mathrm{L})$ of patch is calculated using transmission line model equations [1]. Slot has been created in the ground plane leading to formation of PBG which affects the antenna performance significantly [5-10]. The width and length of the microstrip antenna are determined as follow

$$
W=\frac{1}{2 f_{r} \sqrt{\mu_{0} \epsilon_{0}}} \sqrt{\frac{2}{\epsilon_{r}+1}}=\frac{v_{0}}{2 f_{r}} \sqrt{\frac{2}{\epsilon_{r}+1}}
$$

Where $v_{0}$ is the free-space velocity of light.

$$
\epsilon_{\text {reff }}=\frac{\epsilon_{r}+1}{2}+\frac{\epsilon_{r}-1}{2}\left[1+12 \frac{h}{W}\right]^{-1 / 2}
$$

Where the dimensions of patch along its length have been extended on each end by a distance $\Delta \mathrm{L}$, which is a function of the effective dielectric constant $\epsilon_{\text {reff }}$ and the width-toheight ratio $(W / h)$. A very popular and practical approximate relation for the normalized extension of the length is

$$
\frac{\Delta L}{h}=0.412 \frac{\left(\epsilon_{\text {reff }}+0.3\right)\left(\frac{W}{h}+0.264\right)}{\left(\epsilon_{\text {reff }}-0.258\right)\left(\frac{W}{h}+0.264\right)}
$$

The actual length of the patch can now be determined by

$$
L=\frac{1}{2 f_{r} \sqrt{\epsilon_{r e f f}} \sqrt{\mu_{0} \epsilon_{0}}}-2 \Delta L
$$

The various design parameters of antenna are calculated using the above standard equations [1-2-9].

The patch dimensions are shown in table 1 and the ground plane and PBG dimensions are shown in table 2.

Table 1: Patch Dimensions

\begin{tabular}{|l|l|l|l|l|}
\hline $\mathbf{L}$ & $\mathbf{W}$ & $\mathbf{W 1}$ & $\mathbf{W 2}$ & $\mathbf{Z}$ \\
\hline $30 \mathrm{~mm}$ & $40 \mathrm{~mm}$ & $12.5 \mathrm{~mm}$ & $12.5 \mathrm{~mm}$ & $5 \mathrm{~mm}$ \\
\hline
\end{tabular}


The front view of the S-shape patch and the back view of the proposed antenna with PBG structure is shown if fig. 1 and fig. 2 respectively.

The length and width of the graph in IE3D simulator were taken $60 \mathrm{~mm} \times 60 \mathrm{~mm}$. The simulated results are obtained at feed point $(40,32)$ with 40 no. of frequency points.

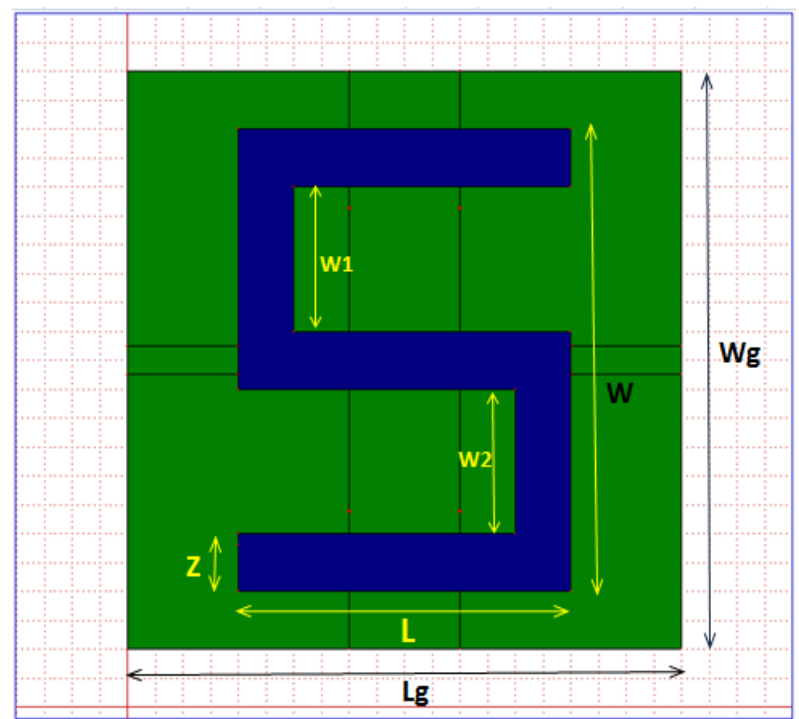

Fig 1: Front view of proposed S-shape microstrip antenna

The proposed S-shape microstrip antenna is nothing but a slotted rectangular patch in which two slots are created to give the shape like letter S. We may also treat it as a dual C-shape microstrip antenna.

Table 2: Ground Plane and PBG Dimensions

\begin{tabular}{|c|c|c|c|}
\hline $\mathbf{L}_{\mathbf{g}}$ & $\mathbf{W}_{\mathbf{g}}$ & $\mathbf{L}_{\mathbf{p}}$ & $\mathbf{W}_{\mathbf{p}}$ \\
\hline $50 \mathrm{~mm}$ & $50 \mathrm{~mm}$ & $10 \mathrm{~mm}$ & $2 \mathrm{~mm}$ \\
\hline
\end{tabular}

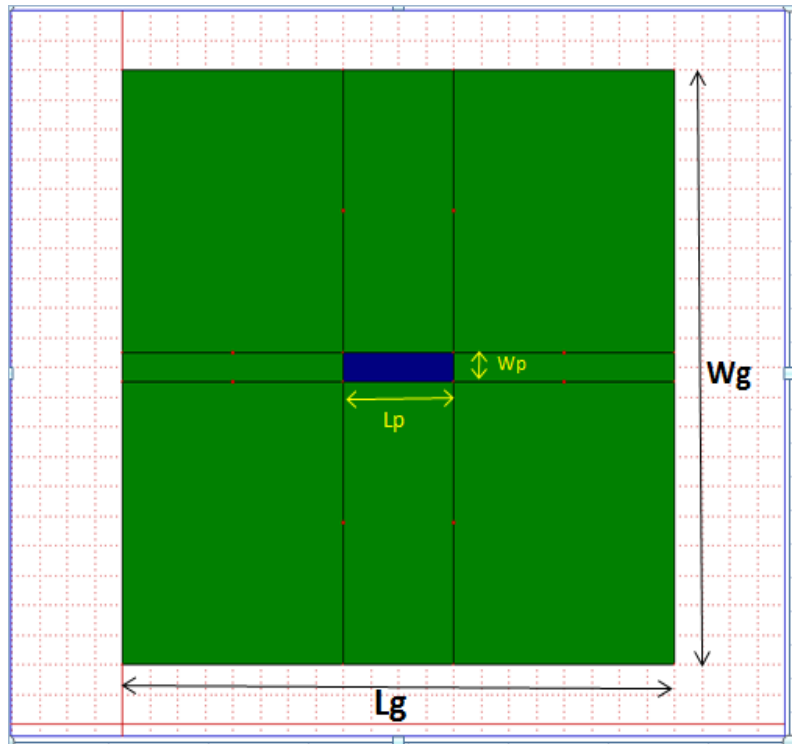

Fig 2: Back view of proposed antenna with PBG structure

\section{RESULTS AND DISCUSSIONS}

Simulating the designed antenna structure over IE3D simulation software shows that the designed antenna structure is suitable to operate in two different frequency bands. The most important term to calculate the bandwidth is return loss curve. The return loss curve is shown in fig. 3 .

From the analysis of the curve it is observed that the antenna is operating in two different frequency bands i.e. S-band and C-band with bandwidths of $1.72 \%$ and $67.23 \%$

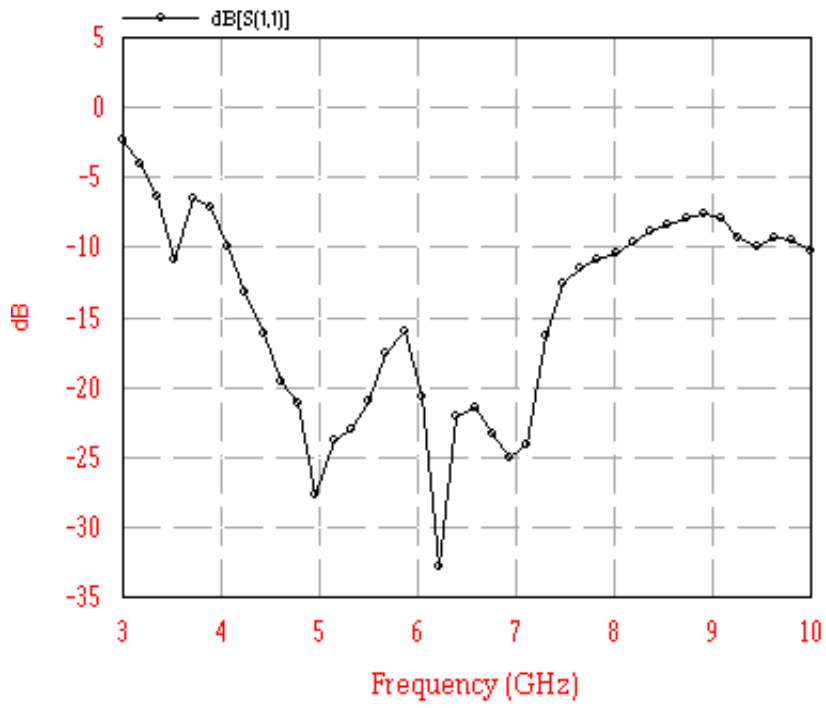

Fig 3: Return Loss Vs Frequency plot

\section{Calculation of Bandwidth}

For frequency band 1

Lower frequency $=3.5384 \mathrm{GHz}$

Higher frequency $=3.60 \mathrm{GHz}$

Center frequency $=3.5692 \mathrm{GHz}$

$\%$ Bandwidth $=\frac{\text { Higher frequency }- \text { Lower frequency }}{\text { center frequency }}$

$$
=1.72 \%
$$

For frequency band 2

Lower frequency $=4.0769 \mathrm{GHz}$

Higher frequency $=8.2051 \mathrm{GHz}$

Center frequency $=6.141 \mathrm{GHz}$

$\%$ Bandwidth $=\frac{\text { Higher frequency }- \text { Lower frequency }}{\text { center frequency }}$

$$
=67.23 \%
$$

From the above calculation it is observed that the designed antenna is suitable for C-band communication with bandwidth of $4.128 \mathrm{GHz}$.

Another very important term which affects the performance of the antenna which is related to the antenna bandwidth is VSWR. Ideally, the VSWR should be below 2. The antenna will only operate at the frequencies where the value of VSWR is less than 2. The VSWR curve of the antenna structure is shown in fig. 4. 


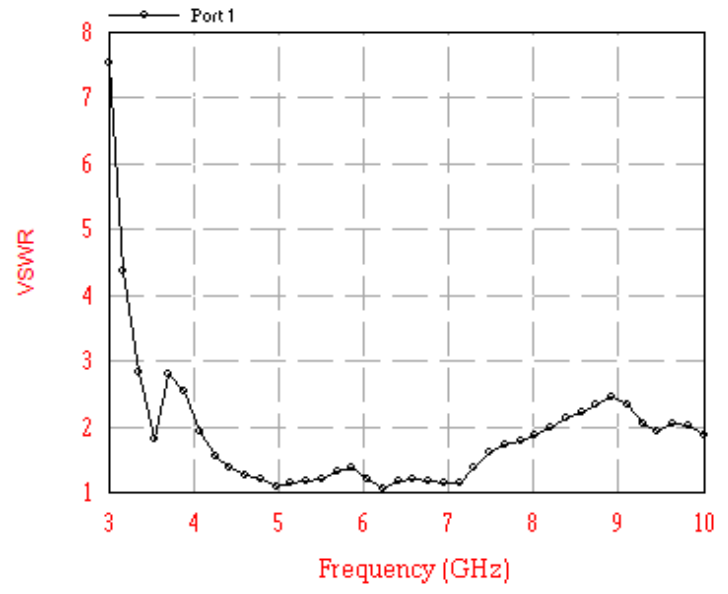

Fig 4: VSWR Vs Frequency plot

As depicted from the curve shown in fig. 5, a very good amount of gain i.e. almost a gain of $6 \mathrm{dBi}$ is obtained.

\section{Gain Vs. Frequency}

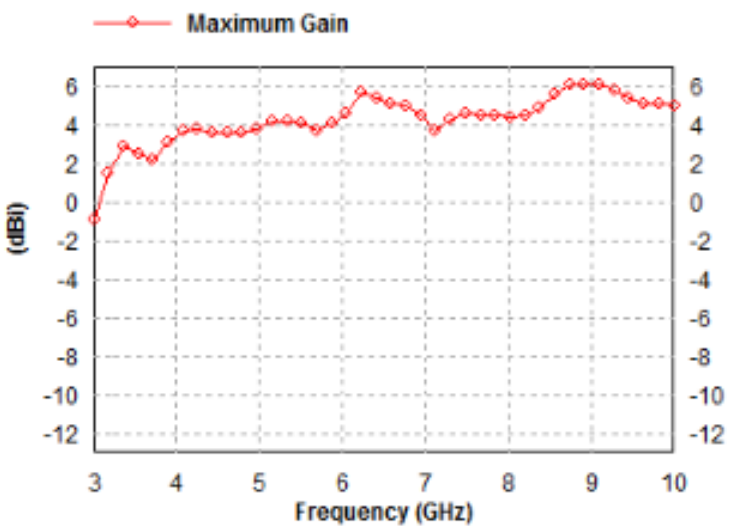

Fig 5: Gain Vs Frequency plot

Another very important parameter related to gain, when antenna performance is to be considered is the directivity. The directivity Vs frequency curve is shown in fig. 6. As observed from the curve shown in fig. 6 , the directivity of $8 \mathrm{dBi}$ is obtained.

\section{Directivity Vs. Frequency}

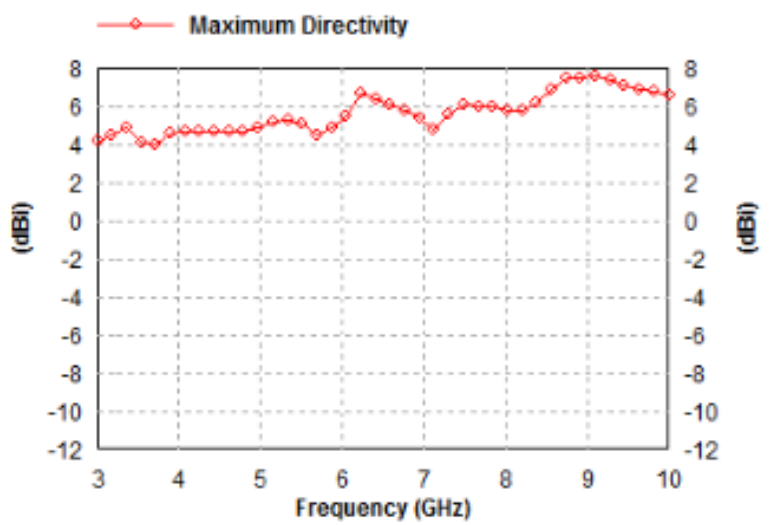

Fig 6: Directivity Vs frequency
Efficiency is a parameter to analyze how well any device can work. In antenna two types of efficiencies are basically calculated i.e. antenna efficiency and radiation efficiency.

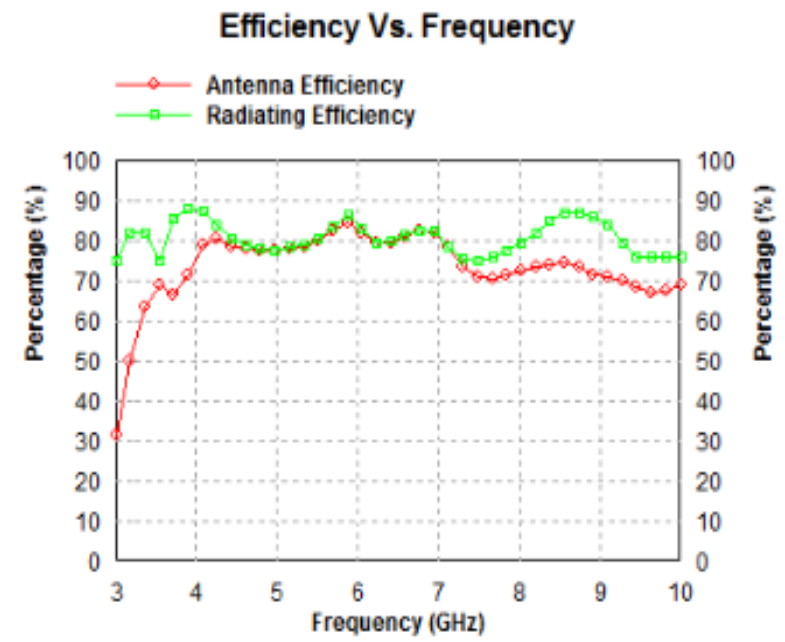

Fig 7: Efficiency Vs frequency

Antenna Efficiency is defined as "The ratio of the total power radiated by an antenna to the net power accepted by the antenna from the connected transmitter." The antenna efficiency curve and radiation efficiency curve are shown in fig. 7. It is observed that the antenna efficiency and radiation efficiency are $85 \%$ and $89 \%$ respectively.

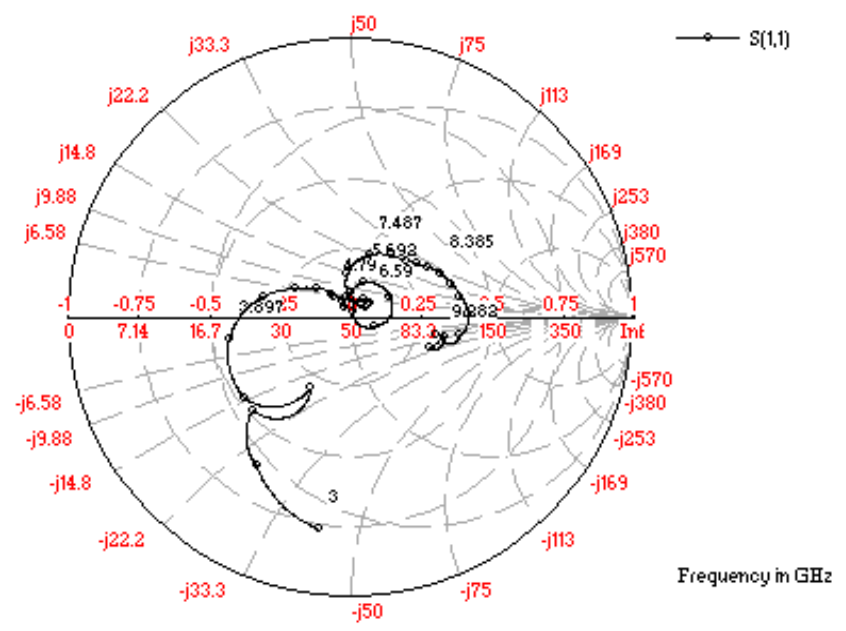

Fig 8: Smith Chart

The smith chart of the proposed antenna is shown in fig. 8 .

Table: 3 shows the maximum negative return loss achieved in two different bands with maximum achieved bandwidth by the proposed MSA.

Table 3: Summary of Results

\begin{tabular}{|c|c|c|c|}
\hline S. No. & $\begin{array}{c}\text { Center } \\
\text { Frequency }\end{array}$ & Return Loss & Bandwidth \\
\hline 1 & $3.5692 \mathrm{GHz}$ & $-11 \mathrm{~dB}$ & $61.6 \mathrm{MHz}$ \\
\hline 2 & $6.141 \mathrm{GHz}$ & $-33 \mathrm{~dB}$ & $4.1282 \mathrm{GHz}$ \\
\hline
\end{tabular}




\section{CONCLUSION}

From the simulation results it is concluded that the proposed S-shape MSA has improved bandwidth which is about $67.23 \%$ in C-band (from $4.076923 \mathrm{GHz}$ to $8.205128 \mathrm{GHz}$ ) and better gain which is $6 \mathrm{dBi}$. The maximum directivity, antenna efficiency and radiation efficiency is $8 \mathrm{dBi}, 85 \%$ and $89 \%$ respectively. A maximum gain of $6 \mathrm{dBi}$ and bandwidth of $4.1282 \mathrm{GHz}$ is obtained by the proposed S-shape MSA. It is observed that proposed S-shape MSA with PBG structure has enhanced the bandwidth with promising gain as compared to the S-shape MSA without PBG structure. Increase in bandwidth provides various advantages like as increasing in channel capacity, increase power handling capacity etc. Hence the proposed antenna deserves perfectly for various wireless applications due to its compact size and improved performance. The antenna is best suited for satellite and wireless communication.

\section{ACKNOWLEDGMENTS}

I am thankful to my research guide "Gyan Prabhakar", coguide "Chetan Choudhary" and Saroj Institute of Technology \& Management, Lucknow, India for providing research facility.

\section{REFERENCES}

11] C.A. Balanis 1997. "Antenna Theory Analysis and Design", John Wiley \& Sons, New York, USA.

[2] G. Kumar, K.P. Ray. 2003. "Broadband Microstrip Antennas", Artech House, USA.

[3] Thana Pakkiam. K, J.S. Mandeep and M.T. Islam, “ Design of Microstrip Antenna for Modern Wireless Communication", $1^{\text {st }}$ IEEE International Symposium on Telecommunication Technologies, 2012

[4] Ali Foudazi, Hamid Reza Hassani and Sajad Mohammad Ali Nezhad "Small UWB Planar Monopole Antenna with added GPS/GSM/WLAN Bands," IEEE transactions on Antenna \& Propagation, Vol. 60, No.6, June 2012.

[5] Rahman M., and Stuchly M.A.: "Wide-band microstrip patch antenna with planar PBG structure" Proc. IEEE Symposium on Antennas and Propagation, Vol. 2, pp. 486-489, 8-13 July 2001.

[6] Sanad M., "Double C-patch antennas having different aperture shapes," Proc. IEEE AP-S Symposium, 21162119, Newport Beah, CA, June 1995.

[7] Yang, F., X.-X. Zhang, X. Ye, and Y. Rahmat-Sami, "Wide-band E-shaped patch antennas for wireless communications," IEEE Trans. Antennas and Propagation., Vol. 49, No. 7, 1091-1100, July 2001.

[8] B.K. Ang and B.K. Chung, "A Wideband E-Shaped Microstrip Patch Antenna for 5-6 GHz Wireless Communications", Progress in Electromagnetic Research, PIER 75, p.p. 397-407, 2007.

[9] D. M. Pozar, "Microstrip Antennas", IEEE Proc., Vol. 80, pp. 79-91, January 1992.

[10] H.Y.D. Yang, "Photonic Bandgap Materials", Electromagnetics, Vol. 19, 1999, pp.255-276.

[11] Xiaofei Shi, Zhihong Wang, Hua Su and Yun Zhao, "A H-type Microstrip Slot Antenna in Ku-band Using LTCC Technology with Multiple Layer Substrates," Proc. IEEE, Vol. 978-1, pp. 7104 - 7106, 2011.

[12] IE3D, Zeland Software Inc, Fremont, CA, USA, 2000.

[13] Fitri Yuli Zulkifi, Faisal Narpati and Eko Tjipto Rahardjo, "S-shaped Patch Antenna Fed by Dual Offset Electromagnetically Coupled for 5-6 GHz High Speed Network" PIER, Vol. 3, No. 2, pp. 163 - 166, 2007.

[14] Bharatendra Singh Niboriya, Chetan Choudhary and Gyan Prabhakar, "Design of H-Shape Wideband Microstrip Patch Antenna With Slots For Wireless Communication" International Journal of Engineering Research \& Technology, IJERT, Vol. 2 Issue 6, June 2013. 